\title{
Esophagitis in Children with Celiac Disease
}

\author{
Wael N. Sayej, ${ }^{1}$ Razan AlKhouri, ${ }^{2}$ Robert D. Baker, ${ }^{2}$ Raza Patel, ${ }^{2}$ and Susan S. Baker ${ }^{2}$ \\ ${ }^{1}$ Digestive Diseases, Hepatology and Nutrition Center, Connecticut Children's Medical Center, \\ School of Medicine University of Connecticut, Framington, CT 06030, USA \\ ${ }^{2}$ Digestive Diseases and Nutrition Center, Women and Children's Hospital of Buffalo, University at Buffalo, NY 14222, USA
}

Correspondence should be addressed to Wael N. Sayej, wsayejmd@yahoo.com

Received 19 April 2011; Accepted 24 May 2011

Academic Editor: J.-P. Buts

Copyright () 2011 Wael N. Sayej et al. This is an open access article distributed under the Creative Commons Attribution License, which permits unrestricted use, distribution, and reproduction in any medium, provided the original work is properly cited.

Objectives. To our knowledge, the occurrence of esophagitis in children with celiac disease (CD) has never been evaluated. The aim of this study is to determine the prevalence of esophagitis in children with CD. Patients and Methods. Between 2003 and 2007, children with biopsy confirmed CD were retrospectively identified. Biopsy reports were reviewed for esophageal inflammation. Biopsy reports of 2218 endoscopies performed during the same period were also evaluated for inflammation. Results. Forty-nine children diagnosed with CD (47\% boys). Nineteen of 49 (39\%) patients with CD had esophagitis (95\% CI 0.23-0.5). Thirty percent of boys and $46 \%$ of girls with CD had esophagitis (95\% CI $0.12-0.40$ ). Overall, $45 \%$ of patients who underwent upper endoscopy had esophagitis. The prevalence of esophagitis in CD (39\%) compared to the prevalence of esophagitis (45\%) in our practice was not significantly different, $P=0.2526$. Conclusion. There was no difference in the prevalence of esophagitis between children diagnosed with $\mathrm{CD}$ at the time of their diagnostic EGD and the prevalence of esophagitis in children without CD. A prospective study to determine whether the esophagitis should be treated with acid suppression or whether the esophagitis heals with the gluten-free diet is warranted.

\section{Introduction}

Celiac disease (CD) is an immune-mediated disease found in genetically susceptible people of North American, European, and Middle Eastern backgrounds. Exposure to gluten (wheat, barley, and rye) initiates an inflammatory cascade leading to intestinal injury. $\mathrm{CD}$ is histologically characterized by blunting of the villous structures and the presence of intraepithelial lymphocytes in the small intestines. The increase in the estimated prevalence of $\mathrm{CD}$ in children from $1: 1000$ to $1: 3000$ to $1: 100$ is likely due to the availability of serologic markers, increased screening, and recognition of vulnerable populations such as Down's Syndrome and type one diabetes [1-3].

The prevalence of esophagitis in children with known gastroesophageal reflux disease (GERD) is estimated at 15$62 \%[4-6]$ and there can be an overlap in the symptoms associated with GERD and CD. The coexistence of esophagitis in children with histologically confirmed CD has not been evaluated. The aim of this study is to determine the prevalence of esophagitis in children with CD.

\section{Materials and Methods}

2.1. Patients. To determine the prevalence of esophagitis in patients with $\mathrm{CD}$, the records of all patients who underwent esophagogastroduodenoscopies (EGD) with biopsies at the Women and Children's Hospital of Buffalo, University at Buffalo, between January 1, 2003 through December 31, 2007, were searched for the diagnosis code 579.0 (Celiac Disease). To determine the prevalence of esophagitis in children undergoing EGD with biopsies, all records of EGD from January 1, 2003 through December 31, 2007 were reviewed. Those who had mucosal biopsies at the time of endoscopy were included in the analysis. Patient demographics, laboratory data, clinical presentation, histology, and endoscopy results were retrieved from office charts, pathology reports, and electronic records. 
Table 1: Patient demographics.

\begin{tabular}{|c|c|c|c|c|c|c|c|c|}
\hline & \multicolumn{4}{|c|}{ Celiac disease population $n=49$} & \multicolumn{4}{|c|}{ Endoscopy with biopsy population $n=2218$} \\
\hline & Number $(\%)$ & Mean & Range & $\mathrm{SD} \pm$ & Number $(\%)$ & Mean & Range & $\mathrm{SD} \pm$ \\
\hline Number & 49 & & & & 2218 & & & \\
\hline Age $(y)$ & & 9.7 & $1-18$ & 5.38 & & 10.51 & $0.25-24$ & 5.68 \\
\hline \multicolumn{9}{|l|}{ Gender } \\
\hline Males & $23(47)$ & & & & $1097(49)$ & & & \\
\hline Age (Y) & & 9.39 & $1-18$ & 5.63 & & 9.55 & $0.25-20$ & 5.34 \\
\hline Esophagitis & $7 / 49(14)$ & & & & & & & \\
\hline Females & $26(53)$ & & & & $1121(51)$ & & & \\
\hline Age (Y) & & 9.98 & $1-18$ & 5.24 & & 11.46 & $0.25-24$ & 5.84 \\
\hline Esophagitis & $12 / 49(24)$ & & & & & & & \\
\hline Esophagitis Present & $19(39)$ & 10.09 & $1-17$ & 4.98 & $997(45)$ & 10.77 & $0.25-24$ & 5.55 \\
\hline \multicolumn{9}{|l|}{ Gender } \\
\hline Male & $7 / 19(37)$ & & & & $560(56)$ & & & \\
\hline Age (Y) & & 9.37 & $2-14$ & 3.98 & & 10.27 & $0.25-22$ & 5.54 \\
\hline Female & $12 / 19(63)$ & & & & $437(44)$ & & & \\
\hline Age (Y) & & 12.18 & $5-18$ & 3.85 & & 11.42 & $0.25-24$ & 5.49 \\
\hline Esophagitis absent & $30(61)$ & 9.56 & $1-18$ & 5.9 & $1221(55)$ & 10.31 & $0.25-24$ & 5.76 \\
\hline \multicolumn{9}{|l|}{ Gender } \\
\hline Male & $16 / 30(53)$ & & & & $537(44)$ & & & \\
\hline Age (Y) & & 9.4 & $1-18$ & 6.34 & & 8.84 & $0.25-24$ & 6.04 \\
\hline Female & $14 / 30(47)$ & & & & $684(56)$ & & & \\
\hline Age (Y) & & 7.95 & $1-17$ & 5.66 & & 11.49 & $0.25-20$ & 5.24 \\
\hline
\end{tabular}

2.2. Upper Endoscopy with Biopsies. The indications for EGD with biopsies included abdominal pain, bloating, diarrhea, weight loss, poor-weight gain, failure to thrive, positive serology for tissue transglutaminase (TTG) or antiendomysial antibody (EMA), reflux symptoms, and failed treatment with acid suppression therapy. Anesthesia was administered by pediatric anesthesiologists. All EGDs were performed using an EG1840K or EG2730K video endoscope (Pentax Medical, Montvale, NJ). During Endoscopy, esophageal (lower, mid, and upper), gastric (antrum and fundus), and duodenal pinch biopsies were routinely obtained using standard biopsy forceps.

2.3. Histology. All biopsies were evaluated by an experienced pediatric pathologist at the Women and Children's Hospital of Buffalo, University at Buffalo [7].

2.4. Statistical Analysis. Statistical analysis was performed by a professional statistician at the University at Buffalo, Buffalo, NY. Statistical analyses were performed with SAS statistical software (version 9.12, 2004, NC, USA). The means procedure, frequency procedure, and $t$-tests were used to evaluate the prevalence of esophagitis in the practice and to compare it to the prevalence in the general population. One-way ANOVA was used to evaluate the significance of the variables versus the presence of esophagitis in patients with CD. The differences between study groups were considered significant when the $P$ value was $<0.05$ or when $95 \%$ CI did not include 1.0 (equivalent to $P<0.05$ ).

\section{Results}

There were 3548 EGD performed between January 1, 2003 and December 31, 2007. Mucosal biopsies were obtained in 2218 EGD and are included in the analysis. Forty nine $(2.2 \%)$ of those had CD (age 1-18yrs, mean 9.7 yrs \pm SD 5.38). Overall, $19(39 \%)$ of those with CD had esophagitis, 95\% CI (0.23-0.51) including one patient that had eosinophilic esophagitis. Of the 2169 patients who did not have CD, $997(45 \%)$ had histologic evidence of esophagitis (56\% males, mean age 10.77 , range $0.25-24$ years) There was no significant difference in esophagitis between the group that had CD and the group that did not. Patient demographics and characteristics are summarized in Table 1. There was no difference between the groups in any of these parameters.

\section{Discussion}

Gastroesophageal reflux and esophagitis are commonly diagnosed in the general pediatric gastroenterology practice and can cause significant morbidity including missed school days and interference with daily activities.

The prevalence of esophagitis in children with CD has never been examined. Collin et al. [8] showed that $0.9 \%$ of adult patients with esophagitis and $0.6 \%$ of those with esophageal reflux symptoms had CD. They reported that the prevalence of esophagitis was $5.2 \%$ in untreated $C D$, $5.6 \%$ in treated CD, and $27 \%$ in symptomatic reflux disease. The reflux symptoms in celiac patients were mild; however, the symptoms were alleviated on a gluten-free diet (GFD). 
Their conclusion was that patients with reflux esophagitis should not be screened for CD. However, Cuomo et al. [9] showed that adult patients with $\mathrm{CD}$ have a higher prevalence of reflux esophagitis than those without $C D$ and suggest that $\mathrm{CD}$ may represent a risk factor for the development of reflux esophagitis. Our data showed no difference in the prevalence of esophagitis between those who have CD and those who underwent EGD but did not have CD. Our population is different from the populations reported on by Cuomo and Collin in that our data is limited to children and adolescents. Our data suggests that it is prudent to obtain esophageal biopsies at the time of the diagnostic EGD for $\mathrm{CD}$ and to consider repeating esophageal biopsies on those who continue to be symptomatic despite GFD and acid suppression.

It is important to note that there is no data on the prevalence of esophagitis in the general population of children and adolescents. This study shows the prevalence of esophagitis in patients who presented with symptoms that required an EGD. It is expected that these patients would have a higher prevalence of esophagitis than those in the general population. Since the prevalence of esophagitis in patients with $\mathrm{CD}$ is statistically similar to the prevalence of esophagitis in patients who did not have CD but patients whose symptoms warranted an EGD, it is reasonable to assume that esophagitis occurs with greater frequency in patients with CD than in the general population.

Since patients with CD did not have to repeat EGD, we do not know if the esophagitis resolved on a GFD. Patients with coexistent $\mathrm{CD}$ and esophagitis showed clinical improvement when treated with both acid suppression and GFD. Thus, we were unable to determine if the clinical improvement was from acid suppression, GFD, or both.

Finally, esophageal biopsies can also exclude eosinophilic esophagitis (EE), a diagnosis that has been on the rise over the past 15-20 years. Although, we only identified one patient with $\mathrm{CD}$ who concomitantly had EE, there are several case reports and reviews on the increased prevalence of $\mathrm{EE}$ in patients with $\mathrm{CD}$ compared to the prevalence of $\mathrm{EE}$ in the general population $[10,11]$.

\section{Conclusion}

There was no difference in the prevalence of esophagitis between children diagnosed with $\mathrm{CD}$ at the time of their diagnostic EGD and prevalence of esophagitis in children without CD undergoing EGD. A prospective study to determine whether there is a need to treat the esophagitis with acid suppression therapy or whether the esophagitis heals with the gluten-free diet is warranted.

\section{Ethical Approval}

The study was approved by the Children and Youth IRB (DB\#2254).

\section{Disclosure}

No benefits in any form have been received or will be received from any commercial party related directly or indirectly to the subject of this paper.

\section{References}

[1] A. Fasano and C. Catassi, "Current approaches to diagnosis and treatment of celiac disease: an evolving spectrum," Gastroenterology, vol. 120, no. 3, pp. 636-651, 2001.

[2] A. Fasano, I. Berti, T. Gerarduzzi et al., "Prevalence of Celiac disease in at-risk and not-at-risk groups in the United States: a large multicenter study," Archives of Internal Medicine, vol. 163, no. 3, pp. 286-292, 2003.

[3] A. Fasano, "European and North American populations should be screened for coeliac disease," Gut, vol. 52, no. 2, pp. 168-169, 2003.

[4] H. B. El-Serag, N. R. Bailey, M. Gilger, and L. Rabeneck, "Endoscopic manifestations of gastroesophageal reflux disease in patients between 18 months and 25 years without neurological deficits," American Journal of Gastroenterology, vol. 97, no. 7, pp. 1635-1639, 2002.

[5] S. Nandurkar and N. J. Talley, "Epidemiology and natural history of reflux disease," Bailliere's Best Practice and Research in Clinical Gastroenterology, vol. 14, no. 5, pp. 743-757, 2000.

[6] W. S. Lee, R. M. Beattie, N. Meadows, and J. A. Walker-Smith, "Gastro-oesophageal reflux: clinical profiles and outcome," Journal of Paediatrics and Child Health, vol. 35, no. 6, pp. 568$571,1999$.

[7] J. J. Lee, R. D. Baker, A. R. Khan, and S. S. Baker, "Childhood esophagitis: then and now," Journal of Pediatric Gastroenterology and Nutrition, vol. 48, no. 1, pp. 37-40, 2009.

[8] P. Collin, K. Mustalahti, S. Kyronpalo, M. Rasmussen, E. Pehkonen, and K. Kaukinen, "Should we screen reflux oesophagitis patients for coeliac disease?" European Journal of Gastroenterology \& Hepatology, vol. 16, pp. 917-920, 2004.

[9] A. Cuomo, M. Romano, A. Rocco, G. Budillon, C. Del Vecchio Blanco, and G. Nardone, "Reflux oesophagitis in adult coeliac disease: beneficial effect of a gluten free diet," Gut, vol. 52, no. 4, pp. 514-517, 2003.

[10] F. Verzegnassi, J. Bua, P. De Angelis, L. Dall'Oglio, G. Di Leo, and A. Ventura, "Eosinophilic oesophagitis and coeliac disease: is it just a casual association?" Gut, vol. 56, no. 7, pp. 1029-1030, 2007.

[11] C. Y. Ooi, A. S. Day, R. Jackson, T. D. Bohane, V. Tobias, and D. A. Lemberg, "Eosinophilic esophagitis in children with celiac disease," Journal of Gastroenterology and Hepatology, vol. 23, no. 7, pp. 1144-1148, 2008. 


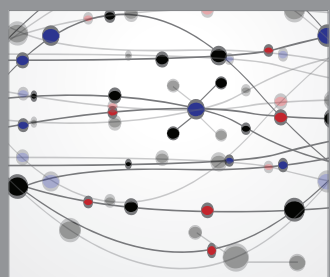

The Scientific World Journal
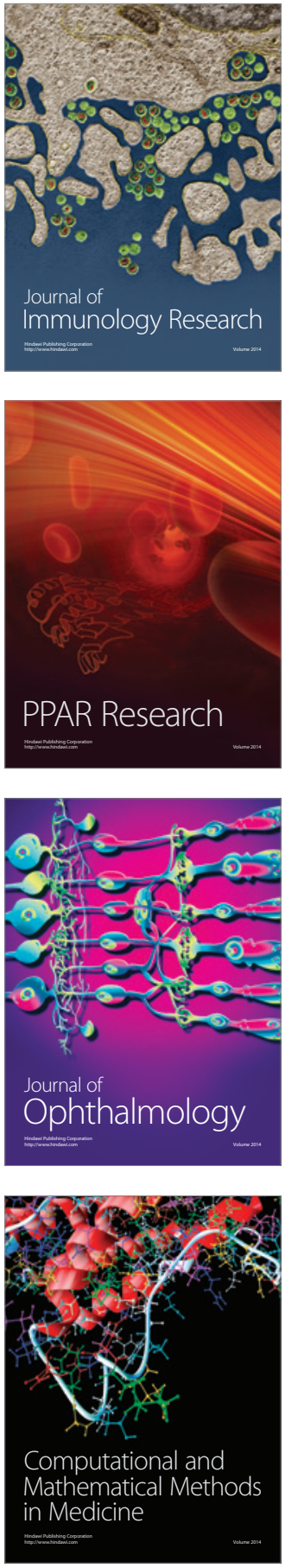

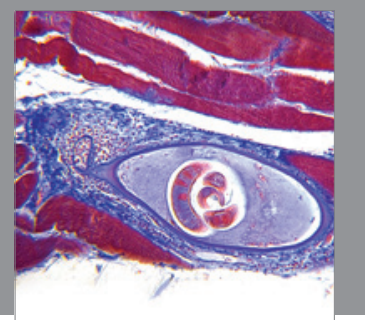

Gastroenterology

Research and Practice
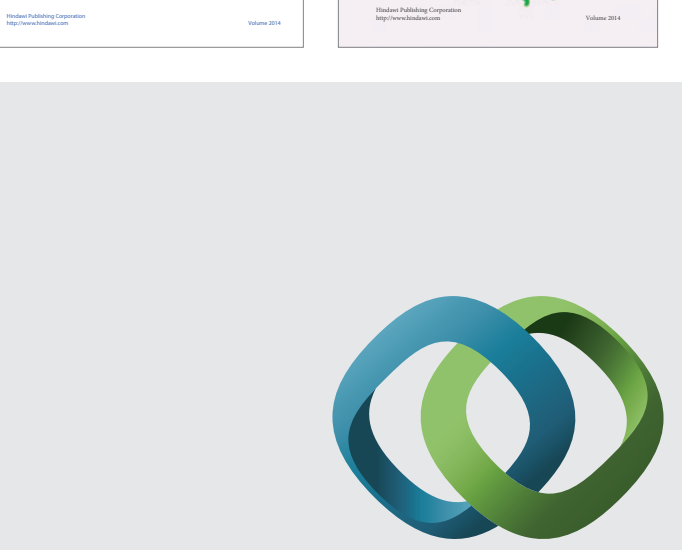

\section{Hindawi}

Submit your manuscripts at

http://www.hindawi.com
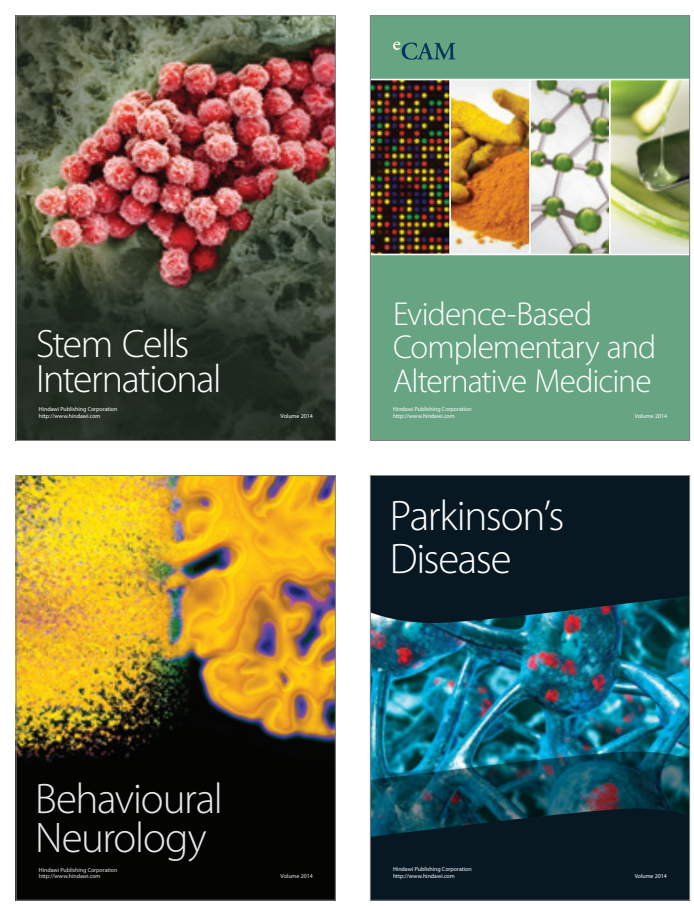

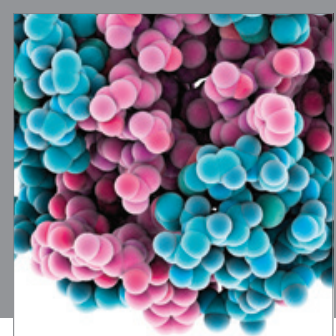

Journal of
Diabetes Research

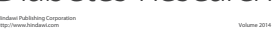

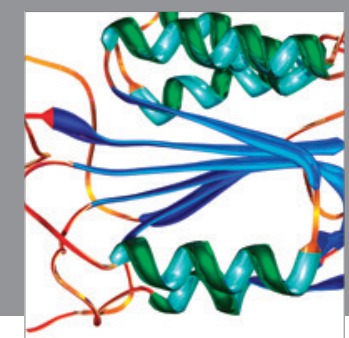

Disease Markers
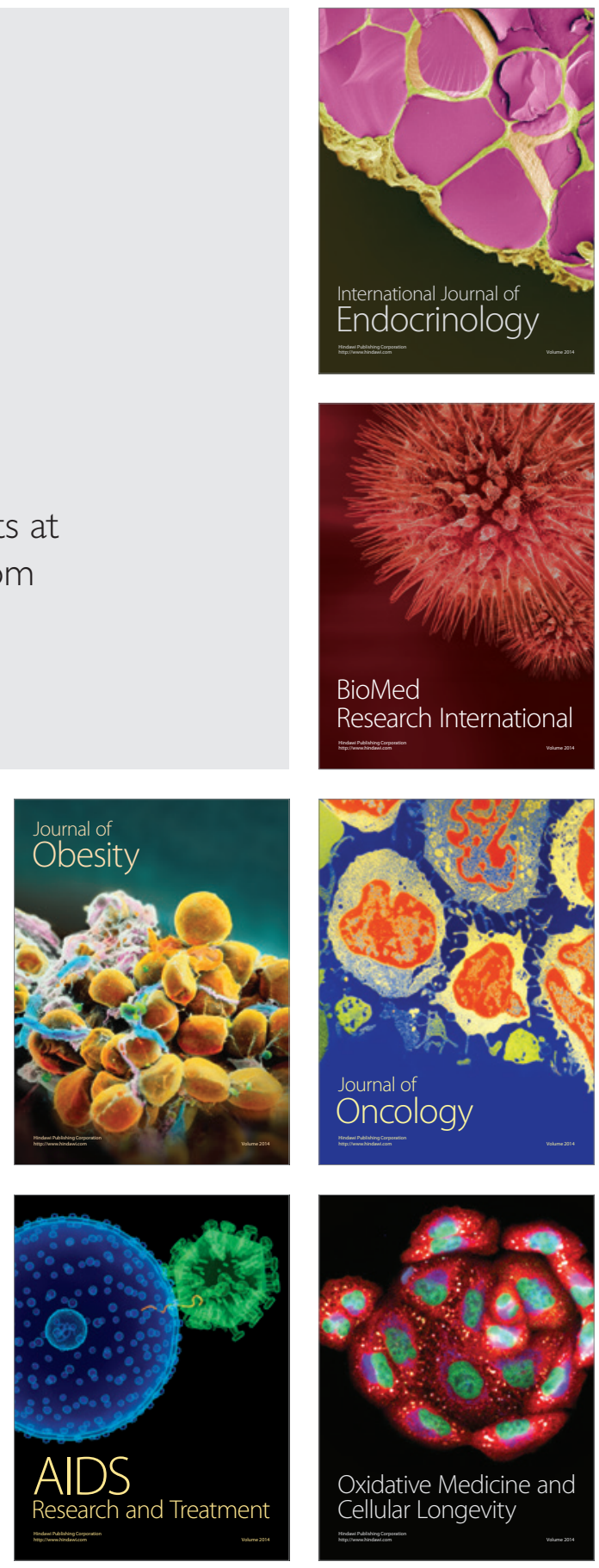